\title{
Biomechanical Test Following Removal of a Dynamic Hip Screw: In Vitro Analysis
}

Anderson Freitas ${ }^{1}$, Jhefferson B. Breta ${ }^{2}$, Joubert Júnior ${ }^{3}$, Antônio C. Shimano ${ }^{4}$, Walter R. Daher ${ }^{2}$, Munir Bessa ${ }^{5}$, Weverton P. De Alcantara ${ }^{2}$, Lucas Sacramento Ramos ${ }^{2}$, Ergon L. Dantas ${ }^{2}$, Ruben J. Aquino ${ }^{2}$

1. Orthopaedics, Hospital of Orthopedic and Specialized Medicine, Brasilia, BRA 2. Orthopedics and Traumatology, Hospital Regional Do Gama, Brasilia, BRA 3. Orthopaedics, Hospital Regional Do Gama, Brasília, USA 4. Orthopaedics, Universidade de São Paulo, São Paulo, BRA 5. Orthopedics and Traumatology, Hospital Regional De Ceilândia, Brasilia, BRA

Corresponding author: Joubert Júnior, joubertvieirajunior@gmail.com

\section{Abstract}

The objective of this study was to evaluate, by means of a static flexural test, the biomechanical parameters necessary for the occurrence of a proximal femoral fracture in a synthetic bone model after the removal of a dynamic hip screw (DHS) and comparing the results obtained with a reinforcement technique using polymethylmethacrylate (PMMA).

Twenty synthetic bones made of the same material and from the same manufacturer were used: ten units as the control group (CG), five units as the test group without reinforcement (TG), and five units as the test group with reinforcement (TGR). The biomechanical analysis was performed simulating a fall over the trochanter using a servo-hydraulic machine. In the control group, the assay was performed with its integrity preserved. In the TG and TGR groups, a DHS model was introduced, and the tests were performed as follows: TG after simple removal of the synthesis material, and in the TGR group, after removal of the synthesis material and filling the orifice of the femoral neck with PMMA.

All groups presented with a basicervical fracture of the femoral neck. The CG group presented a mean of 935 newtons $(\mathrm{N})$ of maximum load and 7.0 joules (J) of energy for fracture occurrence. TG and TGR groups presented, respectively, a maximum load of $750 \mathrm{~N}$ and $1,068 \mathrm{~N}$, and energy of $6.0 \mathrm{~J}$ and $7.3 \mathrm{~J}$. According to the one-way analysis of variance (ANOVA), there was no significant difference in flow load ( $\mathrm{p}=0.16)$, energy to flow $(p=0.16)$, stiffness $(p=0.28)$, maximum load $(p=0.10)$, and energy to fracture $(p=0.54)$ between the studied groups.

The removal of the DHS implant from the synthetic bone did not present a significant increase of the maximum load and the energy necessary for the occurrence of a fracture with the use of the PMMA reinforcement technique.

Received 10/25/2018

Review began 11/18/2018

Review ended 12/01/2018

Published 12/04/2018

๑) Copyright 2018

Freitas et al. This is an open access article distributed under the terms of the Creative Commons Attribution License CC-BY 3.0., which permits unrestricted use, distribution, and reproduction in any medium, provided the original author and source are credited.
Categories: Orthopedics, Quality Improvement, Anatomy

Keywords: femoral fractures, fracture fixation, internal, osteoporosis

\section{Introduction}

Osteoporosis is a public health problem of the world population and a disease that is most prevalent in the elderly female population. This disease is characterized by a reduction of the bone mineral density and thus, a reduction of the mechanical resistance of this tissue. It has, as its main socioeconomic impact, the occurrence of fractures by low energy trauma; of these, the fracture of the proximal end of the femur is the one with the highest mortality rates [1].

The aim of treating these fractures is to allow the resumption of the patient's daily activities as quickly as possible, either by joint replacement (hip arthroplasty) or by fracture osteosyntheses, such as a proximal femoral nail (PFN), cannulated screws, or dynamic hip screw (DHS) [2].

The indications for withdrawal of the synthesis used for a fracture treatment of the proximal femoral end are persistent pain in the gluteal and thigh region, which may be caused by the prominence of the synthetic material (DHS, cannulated screw, or stem), implant failure, or infection [2-3]. After the consolidation of the proximal femoral fracture, removal of implants may cause complications, such as possible fractures of the femoral neck or in the intertrochanteric region, especially in patients with poor bone quality [3-5].

Thus, describing the results by means of a static flexion test simulating a fall over the great trochanter in synthetic bones after removal of a material synthesis (DHS), with and without a reinforcement technique, will allow us to describe the mechanical behavior of this region and determine the real concern in removing this material. 


\section{Cureus}

\section{Materials And Methods}

The aim of this study was to evaluate the resistance and energy required for the occurrence of a proximal femoral fracture in the synthetic bone after removal of the DHS implants and comparing the results obtained with the bone cement reinforcement technique.

Twenty synthetic femurs (Model c1010) from a supplier in Brazil (Nacional Ossos ${ }^{\circledR}$, Jaú-Sao Paulo, Brazil), made of sponge and cortical polyurethane with 10 PCF (pounds per cubic foot) and a $12 \mathrm{~mm}$ medullary canal, were used in this evaluation. Those 20 synthetic femurs (of the same batch and model number) were divided into three groups: a control group (CG), a test group without reinforcement (TG), and a test group with reinforcement (TGR), composed of 10, five, and five units per group, respectively.

The CG was formed by synthetic femurs, internally and externally intact and without previous fractures. In the TG and TGR groups, the synthetic femurs were submitted for DHS implantation using a $12 \mathrm{~mm}$ diameter / $95 \mathrm{~mm}$ long sliding screw, according to Baumgartner's tip apex distance (TAD) of up to $25 \mathrm{~mm}$, assisted by radioscopy in all specimens and withdrawn soon thereafter. In the TG group, a biomechanical test was performed shortly after removing the implant without any reinforcement technique. In the TGR group, after the implant was removed, the synthetic femurs were submitted to a reinforcement technique with polymethylmethacrylate (PMMA) in the sliding screw orifice, introduced anterograde with the assistance of a $20 \mathrm{ml}$ syringe, using $10.7 \mathrm{ml}$ (on average) to fill the space (Figure 1). Normal viscosity PMMA was purchased from Biomecânica ${ }^{\circledR}$ (Jaú-Sao Paulo, Brazil).

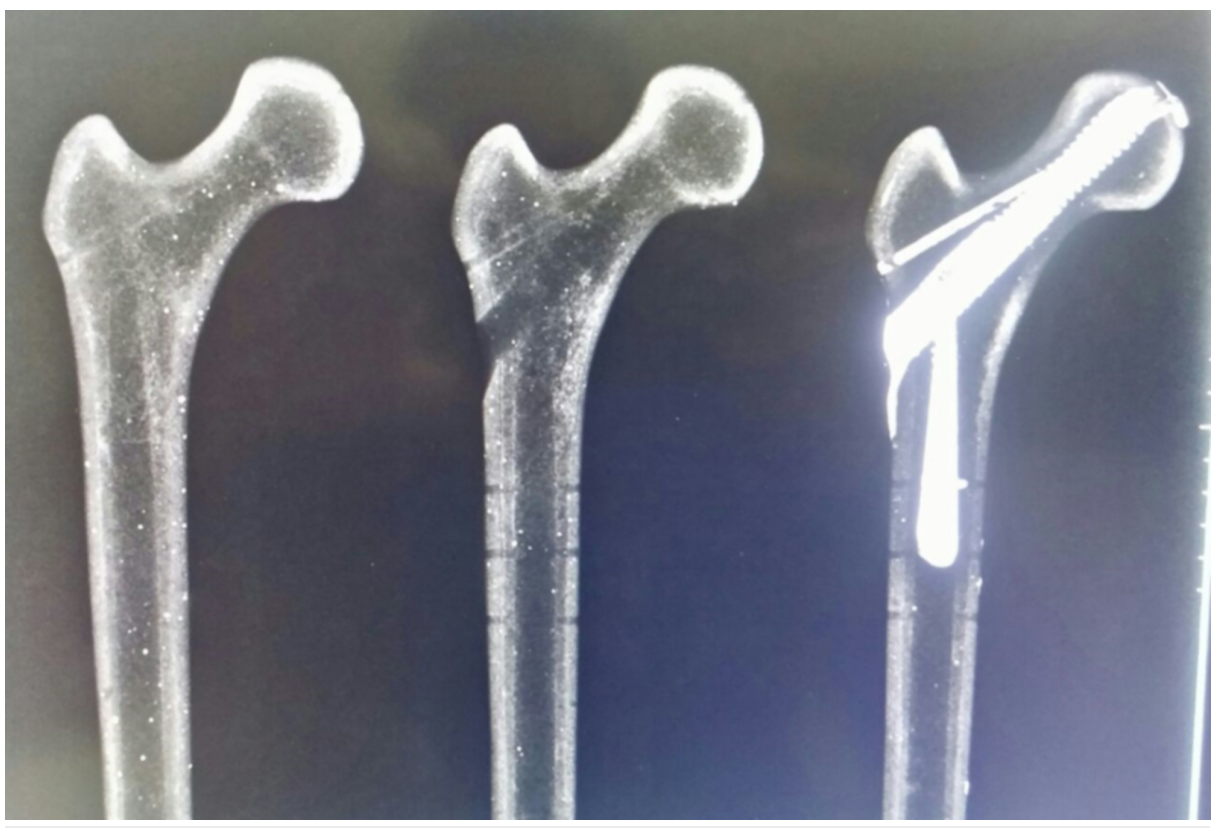

FIGURE 1: Radiographic image of the synthetic models CG, TG, and TGR, respectively, before the biomechanical test

CG: control group; TG: test group without reinforcement; TGR: test group with reinforcement

The bone models that lost cement to the diaphysis beyond the smaller trochanter were excluded from the study (due to the possibility of altering the biomechanics of the proximal femur) since some specimens had an inadvertent filling of part of the femoral canal, causing lack of PMMA in the femoral head.

All samples were sent to the biomechanical testing laboratory. The servo hydraulics MTS 810 Flex Test 40 (MTS Sistemas do Brasil Ltda., São Paulo-SP, Brazil) with a capacity of $100 \mathrm{kN}$ was used statically in flexion.

The femur was attached to the test device leaving $150 \mathrm{~mm}$ of its length out of the device towards the hydraulic piston, positioned at the base of the test machine at $10^{\circ}$ inclination with the horizontal and $15^{\circ}$ internal rotation measured with a digital goniometer. The greater trochanter was kept resting on an $8 \times 2 \mathrm{~cm}$ diameter silicone disc (Figures 2-3). 


\section{Cureus}

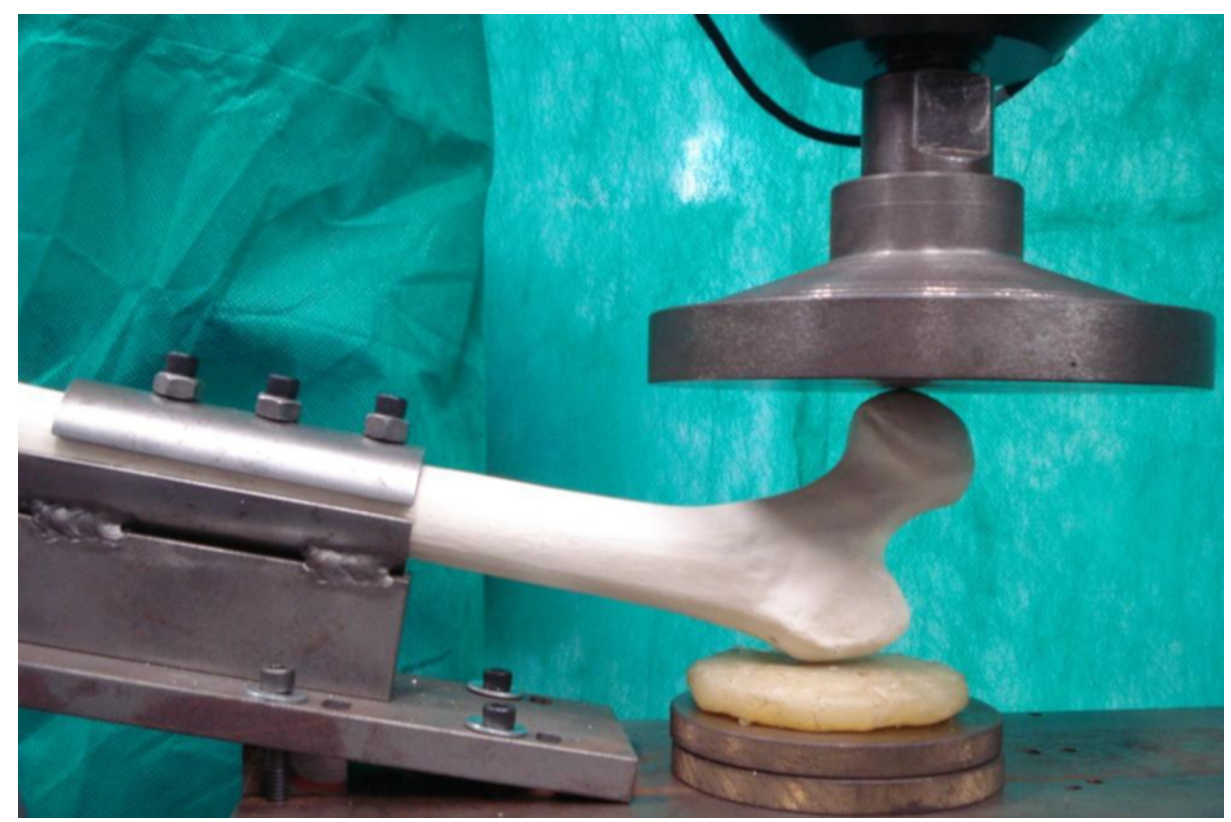

FIGURE 2: Femur adjusted on the device during test

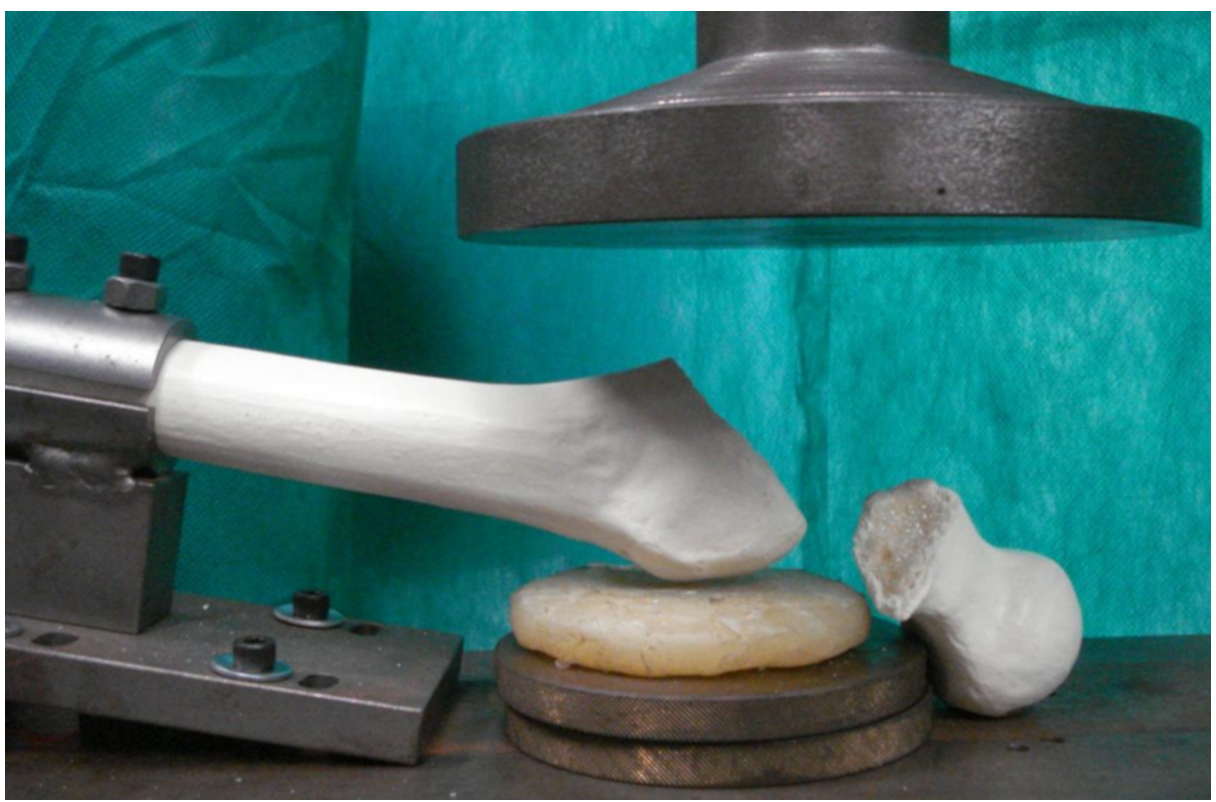

FIGURE 3: Femur after the test

A $40 \mathrm{~N}$ preload was applied at $2 \mathrm{~mm} / \mathrm{s}$ and then the load was applied to the femur head to reach fracture, obtaining the values of maximum load in newton $(\mathrm{N})$ and energy in joule (J).

The results were obtained through an inferential analysis using the values of the selected parameters, composed by the analysis of variance (ANOVA) one-way, with the objective of verifying whether there was a significant difference of the values obtained between CG, TG, and TGR. The significance level was $5 \%$. The statistical analysis was performed by the IBM Statistical Package for Social Sciences (SPSS) Statistics, version 20 (IBM SPSS Statistics, Armonk, NY).

\section{Results}

All specimens tested showed a basicervical fracture (Figure 4). The mean PMMA value used to fill the orifices of the DHS slide bolts of the TGR model was $11 \mathrm{ml}$. 


\section{Cureus}

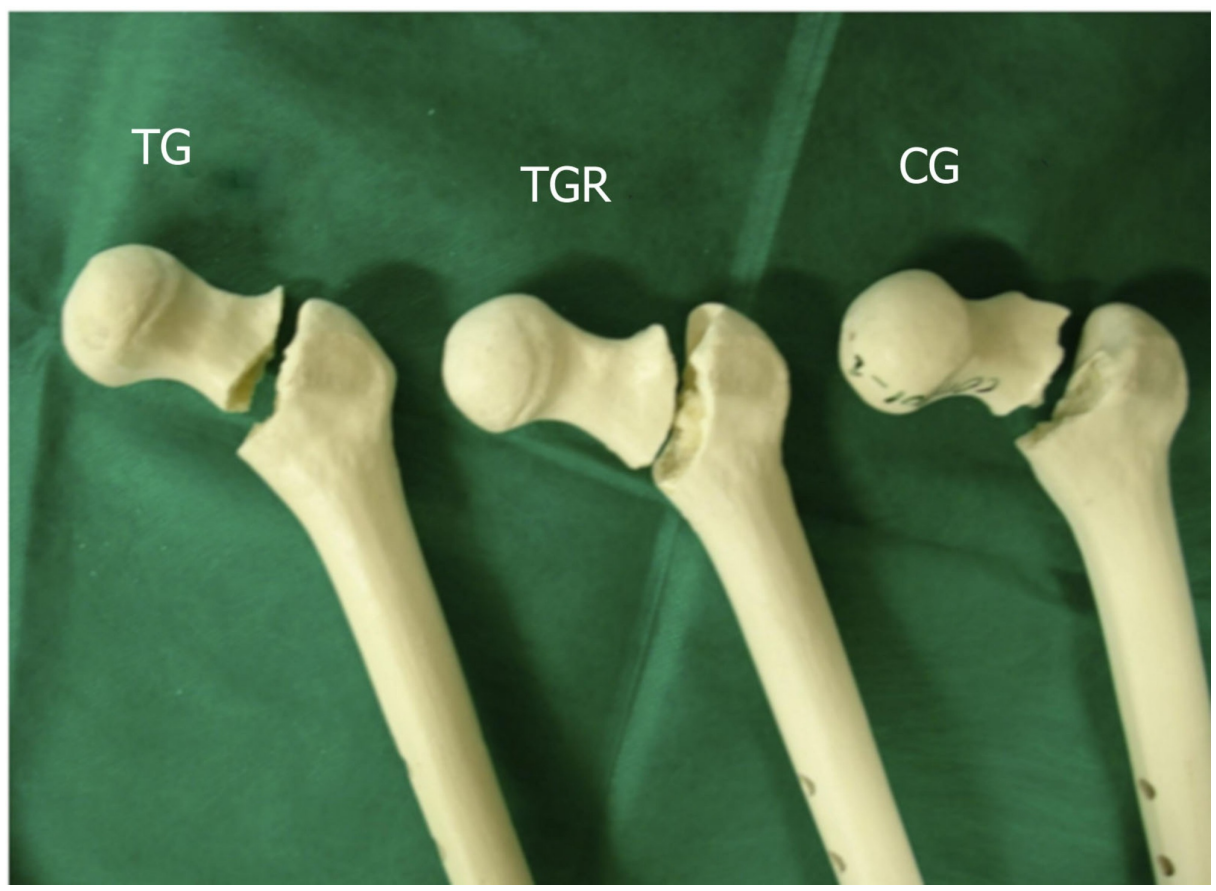

FIGURE 4: All specimens tested showed a basicervical fracture

CG: control group; TG: test group without reinforcement; TGR: test group with reinforcement

The parameters analyzed in the GC, TG, and TGR groups presented the following averages, respectively: flow load in $\mathrm{N}$ (newton): 697, 565, and 808; energy to flow in J (joule): 2.76, 2.08, and 3.32; stiffness in N/mm: 90, 79 , and 102; maximum load in N: 935, 750, and 1,068; and energy to reach fracture in I: 7.1, 6.0, and 7.3 (Tables 1-2). 


\section{Cureus}

\begin{tabular}{|c|c|c|c|c|c|c|c|}
\hline Variable & $\mathrm{n}$ & mean & \multicolumn{2}{|c|}{$\mathrm{Cl} 95 \%$ for the mean } & minimum & maximum & p-value ${ }^{\star}$ \\
\hline \multicolumn{8}{|c|}{ Flow load (N) } \\
\hline CG & 10 & 697 & 559 & 835 & 316 & 1,010 & \\
\hline TG & 5 & 565 & 518 & 612 & 509 & 630 & 0.16 \\
\hline TGR & 5 & 808 & 628 & 989 & 592 & 1,022 & \\
\hline \multicolumn{8}{|c|}{ Displacement to flow (mm) } \\
\hline CG & 10 & 7.71 & 7,0 & 8.4 & 5.3 & 9.5 & \\
\hline TG & 5 & 7.26 & 6.2 & 8.4 & 5.4 & 8.7 & 0.70 \\
\hline TGR & 5 & 7.29 & 6.5 & 9.4 & 5.3 & 9.5 & \\
\hline \multicolumn{8}{|c|}{ Energy to flow (J) } \\
\hline CG & 10 & 2.76 & 2.2 & 3.4 & 0.9 & 3.8 & \\
\hline TG & 5 & 2.08 & 1.7 & 2.5 & 1.4 & 2.7 & 0.16 \\
\hline TGR & 5 & 3.32 & 2.1 & 4.5 & 1.7 & 4.8 & \\
\hline \multicolumn{8}{|c|}{ Stiffness (N/mm) } \\
\hline CG & 10 & 90 & 73 & 107 & 60 & 138 & \\
\hline TG & 5 & 79 & 9 & 89 & 64 & 94 & 0.28 \\
\hline TGR & 5 & 102 & 88 & 117 & 77 & 118 & \\
\hline \multicolumn{8}{|c|}{ TABLE 1: Flow and Stiffness Parameters for the Control and Test Groups } \\
\hline \multicolumn{8}{|c|}{$\begin{array}{l}\text { CG: control group; Cl: confidence interval; J: joule; N: newton; TG: test group without polymethylmethacrylate (PMMA) reinforcement; TGR: test } \\
\text { group with PMMA reinforcement }\end{array}$} \\
\hline
\end{tabular}




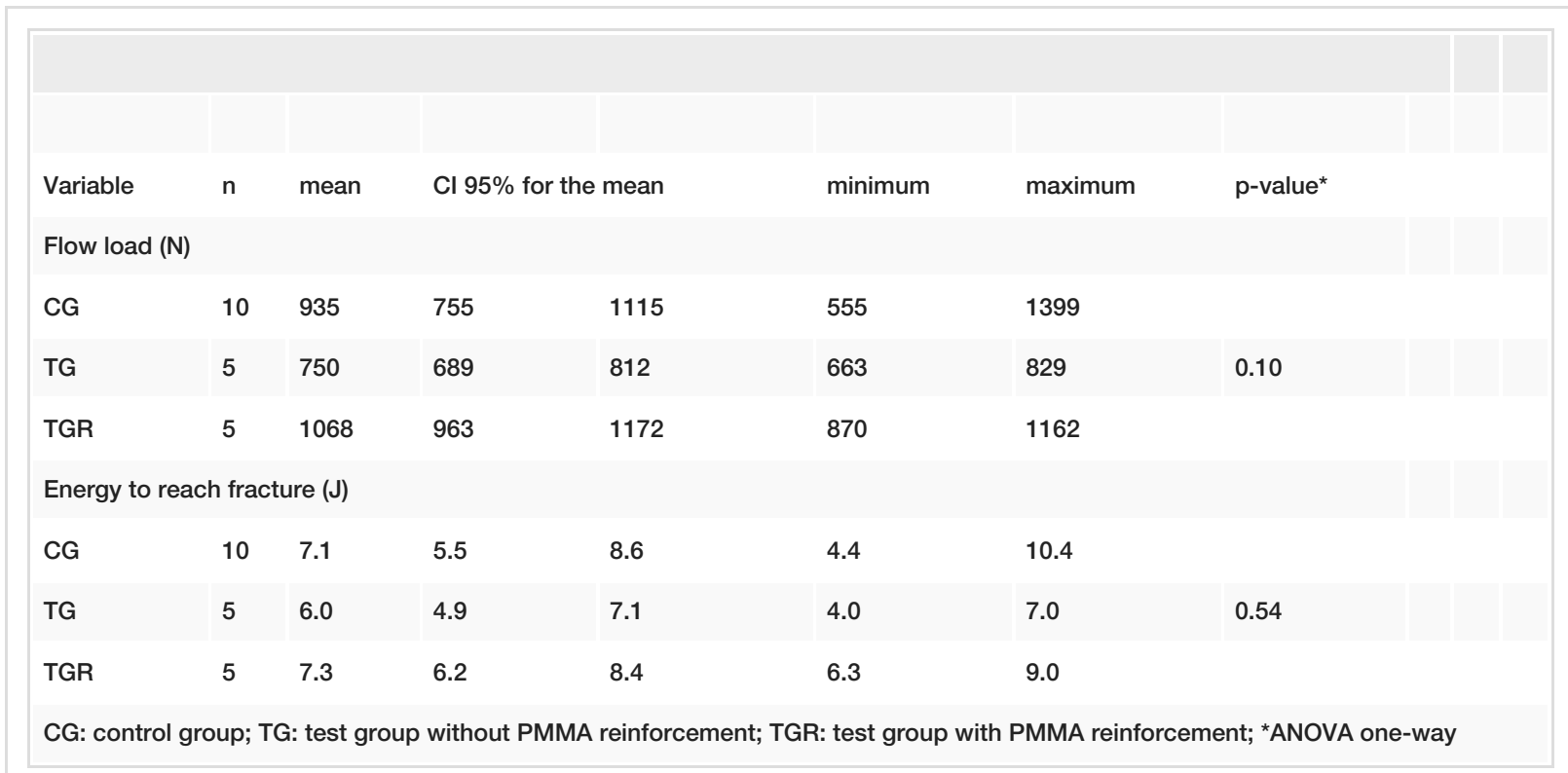

\section{TABLE 2: Maximum Load and Energy Parameters Necessary to Reach Fracture for the Control and Test Groups}

CG: control group; Cl: confidence interval; J: joule; N: newton; TG: test group without polymethylmethacrylate (PMMA) reinforcement; TGR: test group with PMMA reinforcement

According to the one-way ANOVA, there was no significant difference in flow load ( $p=0.16)$, energy to flow $(p=0.16)$, stiffness $(p=0.28)$, maximum load $(p=0.10)$, and energy to reach fracture $(p=0.54)$ between the groups analyzed.

\section{Discussion}

Removal of implants with considerable diameters, such as the DHS after fracture healing, may bring up considerable concerns, especially in osteoporotic bone, so it is important to develop studies that describe the behavior of this region after the withdrawal of the synthesis [5].

The use of bone reinforcement (PMMA) after implant withdrawal has already been studied, although there is a concern regarding the amount used due to the local thermal reaction [6-7]. However, the average volume we reached approaches other studies that demonstrate little local thermal variation.

The choice of synthetic bones was to ensure comparable biomechanical properties between the groups and to eliminate variables found in cadaveric models (bone density, length, and diameter) [8]. As seen in the study by Paiva et al., we noticed that there was a large difference interval in the control group; therefore, we chose to increase the number of synthetic bones to 10 in the control group in order to improve this interval [9].

Although the absolute values are not comparable to studies presented in the literature that used cadaveric bones, the behavior of the increase of load in the TGR and TG groups reduction when compared to the CG allowed us to observe a regular behavior among the trials, even if there was no statistical variance [10-11].

We compared our results to a similar work in which the authors used the same method and synthetic model but using a proximal femoral nail (PFN) instead of a DHS [9]. Paiva et al. described statistically significant results comparing the groups with and without cement filling, a very intriguing result, since the PFN screw used in the study was $10.5 \mathrm{~mm}$ in diameter, smaller than the $12.0 \mathrm{~mm}$ of the DHS screw used in our research. We also expected that using a DHS would lead to the non-invasion of spongy bone in the region of the greater trochanter and that could provide greater resistance as compared to the study using a PFN, although we were not able to confirm these expectations.

Nevertheless, we noticed a change that might have caused the difference. The proximity of the cement filling to the uppermost part of the femoral neck in the PFN group, as compared to our study with DHS, was on the fall over the trochanter. It is, therefore, possible that the closer to this region, the greater the resistance implemented by the reinforcement, leading us to believe that one of the main factors of the increased strength with PMMA in the proximal femoral extremity is not only about the volume of PMMA 
The TG group did not show a significant difference as compared to the CG, leading us to believe that the protection provided by filling the sliding bolt orifice after removing the DHS can be excessive, possibly making it difficult to make a synthesis, in case of a fracture after its withdrawal in the presence of PMMA.

\section{Conclusions}

The experiments of the present study did not show a significant difference between the studied groups; further clinical developments and research are needed to ratify the results presented.

\section{Additional Information \\ Disclosures}

Human subjects: All authors have confirmed that this study did not involve human participants or tissue. Animal subjects: All authors have confirmed that this study did not involve animal subjects or tissue. Conflicts of interest: In compliance with the ICMJE uniform disclosure form, all authors declare the following: Payment/services info: All authors have declared that no financial support was received from any organization for the submitted work. Financial relationships: All authors have declared that they have no financial relationships at present or within the previous three years with any organizations that might have an interest in the submitted work. Other relationships: All authors have declared that there are no other relationships or activities that could appear to have influenced the submitted work.

\section{References}

1. Rodrigues IG, Barros MBA: Osteoporosis self-reported in the elderly: a population-based survey in the city of Campinas, São Paulo, Brazil (Article in Portuguese, English). Rev Bras Epidemiol. 2016, 19:294-306. 10.1590/1980-5497201600020007

2. Yang JH, Jung TG, Honnurappa AR, Cha JM, Ham CH, Kim TY, Suh SW: The analysis of biomechanical properties of proximal femur after implant removal. Appl Bionics Biomech. 2016, 2016:4987831. 10.1155/2016/4987831

3. Kukla C, Pichl W, Prokesch R, Jacyniak W, Heinze G, Gatterer R, Heinz T: Femoral neck fracture after removal of the standard gamma interlocking nail: a cadaveric study to determine factors influencing the biomechanical properties of the proximal femur. J Biomech. 2001, 34:1519-26. 10.1016/S00219290(01)00157-9

4. Kröger H, Kettunen J, Bowditch M, Joukainen J, Suomalainen O, Alhava E: Bone mineral density after the removal of intramedullary nails: a cross-sectional and longitudinal study. J Orthop Sci. 2002, 7:325-30. $10.1007 / \mathrm{s} 007760200055$

5. Eberle S, Wutte C, Bauer C, von Oldenburg G, Augat P: Should extramedullary fixations for hip fractures be removed after bone union?. Clin Biomech (Bristol, Avon). 2011, 26:410-14. 10.1016/.clinbiomech.2010.12.002

6. Strauss EJ, Pahk B, Kummer FJ, Egol K: Calcium phosphate cement augmentation of the femoral neck defect created after dynamic hip screw removal. J Orthop Trauma. 2007, 21:295-300. 10.1097/BOT.0b013e3180616ba5

7. Heini PF, Franz T, Fankhauser C, Gasser B, Ganz R: Femoroplasty-augmentation of mechanical properties in the osteoporotic proximal femur: a biomechanical investigation of PMMA reinforcement in cadaver bones. Clin Biomech (Bristol, Avon). 2004, 19:506-12. 10.1016/j.clinbiomech.2004.01.014

8. Cristofolini L, Viceconti M, Cappello A, Toni A: Mechanical validation of whole bone composite femur models. J Biomech. 1996, 29:525-35. 10.1016/0021-9290(95)00084-4

9. Paiva LM, Macedo Neto SL, Souto DRM, Ferreira GNB, Costa HI, Freitas A: Static bending test after proximal femoral nail (PFN) removal - in vitro analysis. Rev Bras Ortop. 2017, 52:52-56. 10.1016/j.rbo.2017.06.008

10. Fliri L, Sermon A, Wähnert D, Schmoelz W, Blauth M, Windolf M: Limited V-shaped cement augmentation of the proximal femur to prevent secondary hip fractures. J Biomater Appl. 2013, 28:136-143. $10.1177 / 0885328212443274$

11. Beckmann J, Ferguson SJ, Gebauer M, Luering C, Gasser B, Heini P: Femoroplasty - augmentation of the proximal femur with a composite bone cement - feasibility, biomechanical properties and osteosynthesis potential. Med Eng Phys. 2007, 29:755-64. 10.1016/j.medengphy.2006.08.006

12. Basafa E, Murphy RJ, Otake Y, Kutzer MD, Belkoff SM, Mears SC, Armand M: Subject-specific planning of femoroplasty: an experimental verification study. J Biomech. 2015, 48:59-64.

10.1016/i.jbiomech.2014.11.002 